\title{
A model for performance enhancement in competitive cycling
}

\author{
P. Cangley ${ }^{1}$, L. Passfield $^{2}$, H. Carter ${ }^{1}$, M. Bailey $^{1}$ \\ 1 Chelsea School, University of Brighton, Eastbourne, UK \\ 2 Centre for Sports Studies, University of Kent, Chatham, UK
}

Received March 23th 2011 - Accepted 30st August 2011

\begin{abstract}
A 3D cycling model is presented that combines bicycle dynamics, a tyre model, rider biomechanics and environmental factors into a single dynamic system. The system is constructed using Matlab toolboxes (SimMechanics/Simulink) with the aim of identifying mechanical mechanisms that can influence performance in a road cycling time trial. Initial conditions are specified and a variable step ODE solver numerically integrates solutions to the equations of motion. Initial validation compared rider-less self-stability presented in a published "benchmark" with model simulation and found an error of $<1.5 \%$. Model results included the weave eigenvalue becoming negative at $4.2 \mathrm{~m} / \mathrm{s}$ and the capsize eigenvalue approaching a positive value at $6.1 \mathrm{~m} / \mathrm{s}$. The tyre model predicted peak front tyre slip and camber forces of $130 \mathrm{~N}$ and $17 \mathrm{~N}$ respectively which were within $0.9 \%$ of values reported in the literature. Experimental field validation compared actual and model predicted time taken by 14 experienced cyclists to complete a time trial over an undulating 2.5 mile road course. An error level of $1.4 \%( \pm 1.5 \%)$ was found between actual and predicted time. This compares well with the average $1.32 \%$ error reported by existing road cycling models over simpler courses.
\end{abstract}

Key words: Modelling, cycling, bicycle, forward dynamics

Résumé. Un modèle pour l'amélioration de la performance en cyclisme de compétition.

Cet article présente une model dynamique 3D de l'activité cyclisme qui comprend la dynamique de la bicyclette, un modèle de pneumatique, la biomécanique du cycliste et des facteurs environnementaux. Le système est construit en utilisant des boîtes à outils Matlab (SimMechanics/Simulink) dans le but d'identifier les mécanismes mécaniques qui peuvent influencer la performance dans un contre la montre en cyclisme sur route. Les conditions initiales sont spécifiées et un solveur ODE à pas variable intègre numériquement les solutions aux équations du mouvement. Une validation initiale présentée dans une publication benchmark a comparée des résultats obtenus sans cycliste et autostabilisé avec le modèle de simulation. Cette comparaison a montré une erreur inférieure à $1,5 \%$. Les résultats obtenus par ce modèle donnent, en particulier, une valeur propre du lacet devenant négative à $4,2 \mathrm{~m} / \mathrm{s}$ et une valeur propre du tangage approchant une valeur positive à $6,1 \mathrm{~m} / \mathrm{s}$. Le modèle de pneumatique prédit des forces maximales de glissement et de «camber » respectivement, de $130 \mathrm{~N}$ et $17 \mathrm{~N}$. Ces valeurs sont proches (moins de $0,9 \%$ ) de celles rapportées dans la littérature. Afin de valider le modèle, le temps prédit a été comparé à celui réalisé par 14 cyclistes expérimentés lors d une épreuve chronométrée sur un circuit routier vallonné d'une longueur de $4 \mathrm{~km}$. Une erreur de l'ordre de $1,4 \%( \pm 1,5 \%)$ a été trouvée entre le temps réel et le temps prédit. Ce résultat est en adéquation avec l'erreur moyenne de 1,32\% rapportée par les différents modèles existants en cyclisme sur route pour des parcours plus simples.

Mots clés : Modélisation, cyclisme, bicyclette, dynamique directe

\section{Introduction}

The bicycle has been extensively modelled since invention of the safety bicycle by John Starley in 1885 (Wipple, 1899; Carvallo, 1900; Roland, 1973; Meijaard, Papadopoulos, Ruina, \& Schwab, 2007). More recently, the cyclist has been modelled in respect of pedalling (Hull \& Jorge, 1985; Redfield \& Hull, 1986; Neptune \& Hull,
1998) and upper body motion (Soden \& Adeyefa, 1979; Stone \& Hull, 1995) but predominantly in laboratory environments. Few studies have modelled the dynamic environment of field cycling. Those that have, represent the bicycle/rider as an inert point mass and apply prespecified propulsive/resistive forces over a simulation (Olds et al., 1995; Swain, 1997; Martin, Milliken, Cobb, McFadden, \& Coggan, 1998). No published study has 
Table 1. Main model components.

\begin{tabular}{|c|c|c|}
\hline $\begin{array}{l}\text { Bicycle } \\
\text { (Size 59) }\end{array}$ & $\begin{array}{c}\text { Rider } \\
\text { (Typical } 70 \mathrm{~kg} \text { ) }\end{array}$ & $\begin{array}{c}\text { Environment } \\
\text { (Course G10/42) }\end{array}$ \\
\hline 16 rigid bodies with dimension/mass/inertia & 14 body segments (from literature) & Course track (from digital map) \\
\hline $\begin{array}{l}\text { Freedoms: } x \text { y } z \text { translation; roll, pitch, yaw } \\
\text { rotation; steering/cranks/wheels rotation }\end{array}$ & Symmetrical two legged pedalling & Course gradient (from internet) \\
\hline Holonomic + non-holonomic wheel constraints & $\begin{array}{l}\text { Cyclic vertical/horizontal pedal force } \\
\left(\text { phased } 180^{\circ} \text { ) }\right.\end{array}$ & Bicycle/rider aerodynamics \\
\hline $\begin{array}{l}\text { Tyres (slip/camber forces, aligning/overturning } \\
\text { moments) }\end{array}$ & Synchronised bicycle-rider roll & Environmental wind speed/direction \\
\hline Geometry (COM, steer axis, trail, wheelbase) & $\begin{array}{l}\text { Balance, counter-steering and path } \\
\text { following }\end{array}$ & \\
\hline Transmission & Torso and arm rotation & \\
\hline Frame + wheel flex & & \\
\hline
\end{tabular}

been identified which combined the bicycle, rider and environment into the single dynamic system that is necessary if competitive field cycling is to be modelled accurately.

A large number of mechanical variables influence the performance of a competitive cyclist, requiring extensive field testing if optimal combinations are to be identified. Alternatively, modelling enables a limited number of potential optimisations to be identified prior to field investigation. Models that simulate the mechanics of sport typically utilise either inverse dynamics or forward dynamics techniques. A forward dynamics model constructed from mechanical first principles should be developed if a generalised model is required that reproduces performance under a wide range of conditions. The aim of this paper is to describe a forward dynamics model developed for the purpose of enhancing mechanical performance in competitive road cycling.

\section{Study and Model Outline}

The structure of two linked models representing a bicycle and a rider is presented. The bicycle model is extended with a comprehensive tyre sub-model. An environmental model controls road path tracking and aerodynamic, rolling and gravitational resistance forces. The tyre submodel and bicycle "uncontrolled stability" were validated against the literature while model prediction for completion time over an actual road time trial course was compared with a field trial.

The bicycle/rider system was constructed using the Matlab toolbox SimMechanics to model physical entities and Simulink to model control structures. The main subsystems making-up the model are shown in Table 1 . In SimMechanics, a "machine" is built using blocks to represent rigid bodies linked by joints (including closed loops). Rigid bodies and joints are linked with lines that essentially represent 2-way "action-reaction" physical connections providing implicit inertial effects throughout the system. Simulink also utilises a block and connecting line structure, although in this case the blocks represent logical/mathematical functions and connecting lines carry data. A system is actuated by force or motion actuators applied to the joints and bodies with sensors measuring the resulting forces and motion. Constraint blocks allow limits to be placed on forces/motions, and provide gear and rolling wheel functions.

The model was constructed hierarchically. Subsystems were implemented for tyres, transmission, path tracking, aerodynamics and bicycle/rider. The lowest level in the hierarchy was a block representing a single rigid body. Block parameters included mass, inertia tensor, centre of gravity, dimensions and initial orientation with respect to the model's global or local coordinate systems. SimMechanics automatically derives the equations of motion for the complete system. Initial conditions were specified and a variable step ODE solver numerically integrated solutions to meet defined tolerances. The resulting system operated in forward dynamics mode where forces applied to the model resulted in motion subject to the specified constraints.

\section{Bicycle model}

\subsection{Configuration}

The model was configured with a right handed orthogonal coordinate system comprising longitudinal $x$-axis, lateral $y$-axis and vertical $z$-axis. A visualisation of the model with inertias represented by ellipsoids is 


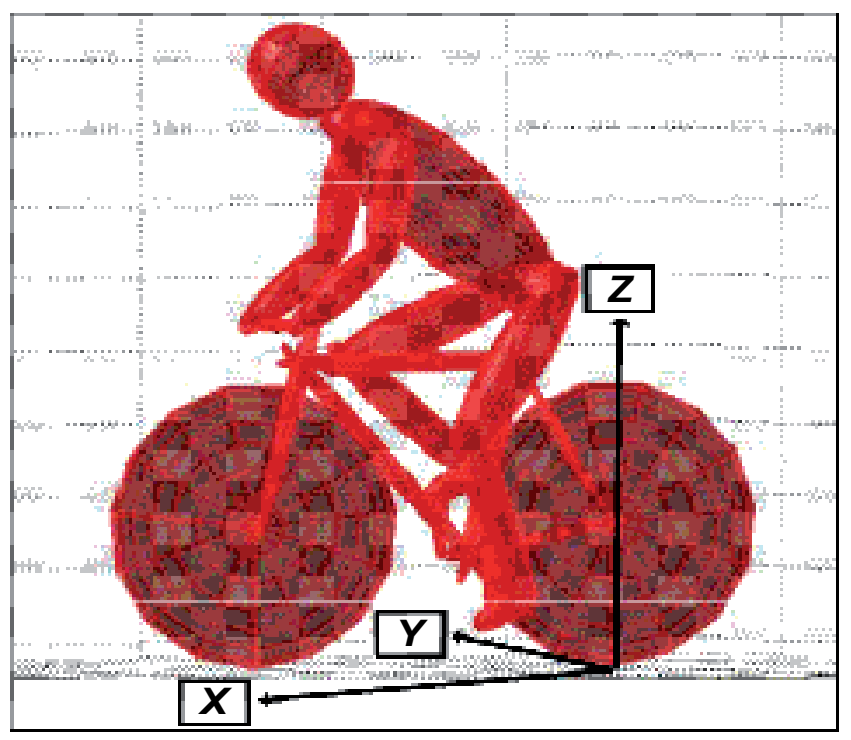

Fig. 1. Model visualisation with segments inertias represented as ellipsoids.

shown in Figure 1. When the system was viewed from the rear, the positive axis orientations were: $x=$ forward, $y=$ left and $z=$ up. The bicycle and rider were laterally symmetrical about the $x z$ plane with the left side being defined as contra-lateral and the right side as ipsi-lateral. Additionally a right handed steering axis was orientated positively upwards.

The global origin was located at the rear wheel/ground contact point and gravity acted downwards at $9.81 \mathrm{~m} / \mathrm{s}$ / s. The bicycle had degrees of freedom (DOF) for longitudinal, lateral and vertical translation together with roll, yaw and pitch rotation. All motion was defined about the ensemble centre of mass (COM) projected vertically down to the ground plane resulting in a location approximately midway between the front and rear tyre contact point. Additional DOF were enabled for rotation of the steering, chainring/cranks and both wheels.

The bicycle reference configuration was stationary, upright, straight ahead with the ipsi lateral crank arm pointing vertically upwards (a crank position defined as top dead centre (TDC)). Bottom dead centre (BDC) was defined as the ipsi-lateral crank arm pointing vertically downwards after crank spindle rotation. A single COM was specified for the complete bicycle/rider and located by application of a force balance. The longitudinal COM was found by balancing the system about the $z$-axis. Gravity was then changed to act longitudinally and the system re-balanced about the $x$-axis followed by iterative $z$-axis and $x$-axis balancing to arrive at a stable COM. The bicycle/rider frontal area was measured using the SimMechanics visualisation tool and the centre of pressure
(COP) relative to the $\mathrm{COM}$ calculated using available algorithms (Heil, 2002).

\subsection{Frame}

The dimensions and mass of the bicycle were taken from measured values for a commercially available bicycle of size 59. A front and rear frame were specified separately with the rear frame comprised of six rigid bodies modelled as tubes plus the rear wheel. The front frame comprised handle bars, stem, fork and front wheel and was connected to the rear frame by a steering joint with its axis inclined upwards at $72^{\circ}$ to the left horizontal. Only one seat stay, chain stay and fork arm were modelled and placed on the bicycle longitudinal centre line. The mass of each body was obtained by weighing or by reference to the manufacturer's specifications. The inertia tensor of each body was derived from its dimensions, mass and shape/density using algorithms provided by SimMechanics. Flexibility was built into the frame by enabling the steering joint to additionally rotate about the longitudinal axis ( $x$-axis). A spring/ damper was placed on this rotation axis to control the level of flex to manufacturer specifications.

\subsection{Wheels}

Both wheels were modelled as knife-edge rigid discs rotating about a hub joint. The inertial mass of each wheel was distributed evenly between the hub and the rim utilising SimMechanics algorithms for a rotating disc. Wheel lateral flexibility was modelled by enabling additional hub rotation about the $x$-axis with the level of flex being controlled by a spring/damper to meet manufacturer specifications. Wheel rotation and translation were related by a non-holonomic constraint which enforced pure rolling without slip while holonomic constraints controlled each wheel's relationship to the ground. Specifically, a sine function controlled wheel (and frame) vertical oscillation simulating road surface and tyre vertical compliance. The tyres were not modelled in a physical sense but the forces and torques generated by the front and rear tyre were derived analytically and applied to the wheel hub (see Tyre model below).

\subsection{Transmission}

A laterally orientated crank spindle was located at the junction of the bicycle frame seat and down tubes rotating about a lateral axis ( $y$-axis). Crank arms were welded at $90^{\circ}$ to each end of the crank spindle and orientated in $180^{\circ}$ opposition. To assist in the system description, conceptual pedals were positioned at the end of each crank arm (although the pedal mass was included in the foot body). The drive transmission from the crank 


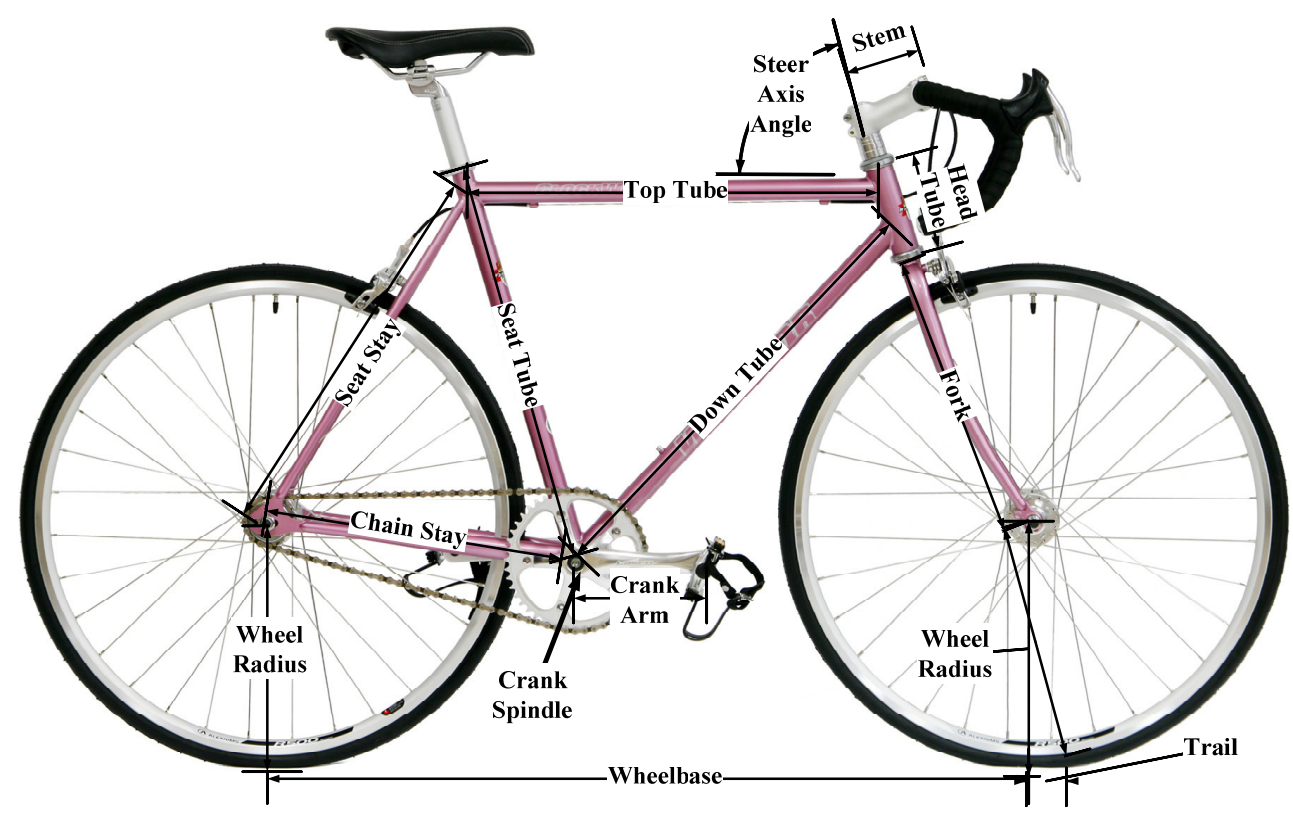

Fig. 2. Bicycle geometry.

to the rear wheel was modelled as follows: Gear wheels fitted to the crank spindle and rear axle connected a rotating drive shaft running longitudinally from the crank spindle to the rear axle. The drive shaft transmitted propulsive torque from the crank to the rear wheel. The numbers of teeth on the gear wheels were adjusted to set the overall gearing ratio.

\subsection{Balance}

The model included gravitational forces and therefore the bicycle had to be actively controlled to remain upright (i.e. an inverted pendulum). Balance was maintained with a proportional-integral-derivative (PID) controller that countered roll by applying a torque to the steering joint that turned the front wheel in the direction of any fall. This torque is normally applied by the rider's arms via the handlebars but in the current model version was applied directly to the steering joint. The resulting steering torque was then modified by a second PID that ensured the bicycle tracked a defined path (see Path tracking $\S 5.1)$.

\subsection{Steering}

Steering was modelled as a joint torque applied at the steering axis linking the front and rear frames. The effects of the steering function were dependent on the front frame geometry that primarily comprised the steering axis inclination $\left(72^{\circ}\right)$, wheelbase $(0.99 \mathrm{~m})$ and trail $(0.056 \mathrm{~m})$, and are shown in Figure 2. Trail was a
Table 2. Rider segments.

\begin{tabular}{llc}
\hline Limb & Segments & $\begin{array}{c}\text { Number of } \\
\text { Segments }\end{array}$ \\
\hline Leg $(\times 2)$ & Thigh, Shank, Foot & 6 \\
Arm $(\times 2)$ & Upper Arm, Forearm & 4 \\
Upper Body & $\begin{array}{l}\text { Pelvis, Torso, Shoulders, } \\
\text { Head }\end{array}$ & 4 \\
\hline
\end{tabular}

critical parameter as it regulated the roll and steer necessary to keep the bicycle upright due to its influence on the degree of front end pitch that occurred with steering (Roland, 1973).

\section{Rider model}

\subsection{Structure}

The rider was constructed from 14 rigid bodies as shown in Table 2. The dimension, mass and inertia tensor of each segment were taken from Redfield and Hull (1986) or calculated by SimMechanics. The pelvis was fixed to the top of the bicycle seat tube, the forearms to the handle bars and the feet to the pedals. Segments and their inertia tensors were symmetrically distributed about the sagittal plane. The leg and arm segments were linked by revolute joints enabling rotation about the $y$ axis (except the shoulders and hips which were modelled by spherical joints). The torso and pelvis were linked by a revolute joint enabling upper body lateral rotation about the $x$-axis. 


\subsection{Pedalling}

Each leg together with the seat tube and crank arm comprised a closed loop 5-bar linkage with two DOF. The crank angle controlled one freedom while the other was controlled by an interpolated look-up file that specified the ankle angle at each degree of crank rotation. The ankle angle profile (which was approximately sinusoidal) was obtained by digitising data from Redfield and Hull (1986). The bicycle/rider was propelled by direct application of vertical and horizontal forces to each pedal. The pedal force profile for the ipsi-lateral pedal over a cycle was obtained from pedal force data measured in our laboratory for power values of 130, 200, 270, 340 and $410 \mathrm{~W}$ (Bailey, Nesi, Passfield, \& Carter, 2006). The model used this data in $2 \mathrm{D}$ lookup tables that returned vertical and horizontal pedal force at each time step from the interpolated input of power and crank angle. Pedal forces up to a limit of $700 \mathrm{~W}$ were extrapolated by fitting a cubic spline. Only rolling starts were modelled in the current version making the upper limit sufficient to ensure that joint torques did not become physiologically infeasible. Forces for the contralateral pedal were implemented as $180^{\circ}$ offset to the ipsilateral pedal. Thus while pedalling forces are normally a result of leg joint torques, in this model the leg pedalling motion was driven by pedal forces.

\subsection{Upper Body}

Few cycling models implement upper body forces and motion although they have a significant effect on performance (Soden \& Adeyefa, 1979). In the present model, a PID controlled upper body lean about the x-axis in opposition to the bicycle roll generated by pedalling in order to maintain the ensemble COM above the wheelbase (corrected for centrifugal force). Upper body rotations about the $y$-axis and $z$-axis were not included. Steering was implemented by applying a torque directly to the steering joint

\subsection{Cadence}

In the present model, cadence was uncontrolled being a resultant of the applied torque and resistive forces. Over the experimental time trial course, the gradient and power values resulted in a cadence range of 70 to $115 \mathrm{rpm}$, values that were considered acceptable for a competitive cyclist. An initial-condition velocity of $8 \mathrm{~m} / \mathrm{s}$ was implemented in field trials to simulate a rolling start.

\section{Environment model}

\subsection{Path Tracking}

The bicycle followed a path defined by eastings and northings. The bicycle was initially aligned with the northings and as it proceeded, deviations from the required eastings were corrected by steering inputs. For the field validation, northing/easting coordinates for the first 2.5 miles of a time trial course were captured from a digital map. The height of each coordinate was obtained from Google Earth as these were found to be more accurate than Ordinance Survey values. A sub-system monitored the bicycle position along the northing coordinate at each time step and obtained the required easting coordinate from a lookup-file that interpolated between the measured intervals. Steering torque was applied after the error between the required and actual easting position was minimised by a PID controller.

\subsection{General Resistive Forces}

Aerodynamic resistance and changes in gravitational resistance due to road gradient were modelled analytically (i.e. by Simulink equations) and applied in the $x$-axis and $y$-axis of the global coordinate system at the bicycle/rider COP (aerodynamic) and COM (gravitational). Rolling resistance was incorporated in the tyre model, while inertial resistance due to acceleration required no explicit modelling as it is applied implicitly by SimMechanics. Transmission frictional losses were ignored as power was measured at the rear wheel.

\subsection{Aerodynamic resistance}

The induced air flow due to bicycle motion was modified by both the speed and direction of the environmental wind in order to calculate the apparent air flow. Apparent air flow was resolved into $x$ and $y$ components before calculating the resistive forces applied to the bicycle/rider COP with the following expression

$$
\begin{aligned}
& F_{A x}=0.5 \cdot p \cdot C D A \cdot V_{x}^{2} \\
& F_{A y}=0.5 \cdot p \cdot C D A \cdot V_{y}^{2}
\end{aligned}
$$

where the $x$ and $y$ subscripts denote the longitudinal and lateral axes respectively, $F_{A}$ was the aerodynamic resistive force, $V$ was the apparent air velocity, $p$ was the air density and $C D A$ was the coefficient of drag area (drag multiplied by frontal area). Initial values were set at $p=1.22 \mathrm{~kg} \cdot \mathrm{m}^{3}$ (typical sea level) and $C D A=0.37$ which was typical for an average sized cyclist on a road racing bicycle without tribars (Martin et al., 1998; Kyle, 1994). The CDA value was modified dynamically throughout a simulation due to changes in the road/ bicycle heading relative to the environmental wind. The yaw angle of the bicycle from the right horizontal was monitored to ensure the resistive forces were applied as values opposing motion.

\subsection{Environmental wind}

Environmental wind strength and direction were specified with initial values although both could vary 
during a trial if a measured profile was available. The wind vector was resolved into $x$ and $y$ axis components with the following expressions

$$
\begin{aligned}
& V_{W x}=V_{W} \cdot \cos W_{\theta} \\
& V_{W y}=V_{W} \cdot \sin W_{\theta}
\end{aligned}
$$

where $V_{W}$ was the wind velocity and $W_{\theta}$ was the wind angle from the right horizontal. The resolved components were then subtracted from the induced air velocities measured on the $x$-axis and $y$-axis to arrive at the apparent air velocities for each axis. The model re-calculated the effect of wind on apparent air velocity at each time step because the bicycle/road direction changed continuously.

\subsection{Gravitational resistance}

The gradient changed frequently in the field trial so model gravitational resistance was calculated and applied at each time step from the following expression:

$$
F_{G}=M \cdot g \cdot \sin \left(\arctan \left(G_{R}\right)\right)
$$

where $F_{G}$ was the gravitational resistive force, $M$ was the ensemble mass and $g$ was the force due to gravity. The biomechanics of pedalling could theoretically be affected by the orientation of the bicycle and rider to the vertical (i.e. gravity). However, the bicycle/rider was not rotated about the $y$ axis to reflect the slope of the ground as the effect on pedalling has been found to be minimal (Caldwell, Li, McCole, \& Hagberg, 1998). The resistive force was resolved into $x$-axis and $y$-axis values and then applied in opposition to the ensemble direction of travel at each time step.

\section{Tyre model validation}

\subsection{Introduction}

The handling and path-following of a bicycle are substantially influenced by the behaviour of two small contact patches linking the tyres to the road, making an accurate tyre model critical to the fidelity of bicycle performance. If a bicycle is to turn, the two tyres must provide equal and opposite inward forces opposing the conceptual "centrifugal force" acting outwards. More exactly, the centripetal acceleration into a turn is driven by the magnitude of the lateral tyre force provided by tyre slip and wheel camber.

A transient step-change steering input was selected to exercise the tyre model as it highlighted the temporal development of tyre forces/moments compared to more progressive steering control. In a competitive sport context, the chosen manoeuvre equated to a cyclist changing direction to exploit a gap during the final sprint of a road race (similar to the initial action of the "lane change" manoeuvre used in vehicle testing).

\subsection{Tyre model structure}

Two sub-systems generated front and rear tyre forces/ moments in response to motion inputs. Tyre slip angle and lateral tyre force were calculated respectively from

$$
\begin{gathered}
\alpha=\arctan \left(\frac{V_{y}}{V_{x}}\right) \\
F_{y}=C_{\alpha} \cdot \alpha+C_{\gamma} \cdot \gamma
\end{gathered}
$$

where $\alpha$ was slip angle, $V_{y}$ was wheel lateral velocity, $V_{x}$ was wheel longitudinal velocity, $F_{y}$ was lateral force, $C_{\alpha}$ was cornering stiffness, $C_{\gamma}$ was camber stiffness and $\gamma$ was camber angle. The first term in the lateral force equation calculated slip force, the development of which was lagged by a first order lag function with a time constant equal to relaxation length divided by speed. The second term calculated camber force which was not lagged in this derivation. Aligning moment and overturning moment were calculated respectively from

$$
\begin{aligned}
& M_{z}=C_{m \alpha} \cdot \alpha+C_{m \gamma} \cdot \gamma \\
& M_{x}=F_{z} \cdot \delta_{c}
\end{aligned}
$$

where $M_{z}$ was aligning moment, $C_{m \alpha}$ was aligning moment stiffness, $C_{m \gamma}$ was aligning moment camber stiffness, $M_{x}$ was overturning moment, $F_{z}$ was vertical tyre force and $\delta_{c}$ was vertical force lateral offset due to camber. Only aligning moment was lagged and calculated as for slip. Rolling resistance was calculated as $\mu \cdot m \cdot g$ where $m$ was bicycle/rider mass, $g$ was the gravitational constant and $\mu$ was the rolling resistance coefficient obtained from an experimental "coastingdown" test.

\subsection{Tyre parameter identification}

The identification of tyre parameters was critical to model fidelity and the model values were selected after examining the experimental measurement of bicycle tyres reported in the literature. The reported values showed considerable variance due to differing test conditions. These differences were analysed in detail to identify the values most appropriate for this study.

A rolling resistance coefficient for the model was obtained from a study by Kyle (2003) which presented a comprehensive experimental tyre test. The effects of tyre type, road surface and inflation pressure were evaluated and a coefficient of 0.004 was calculated for a $23 \mathrm{~mm}$ clincher tyre at 95 psi rolling on smooth tarmac.

\subsection{Tyre model assumptions}

The lateral force/slip angle relationship was assumed to be linear as slip angle was expected to remain below $5^{\circ}$ in the experimental time trial (Gillespie, 1992). Longitudinal slip was neglected as the magnitude of 


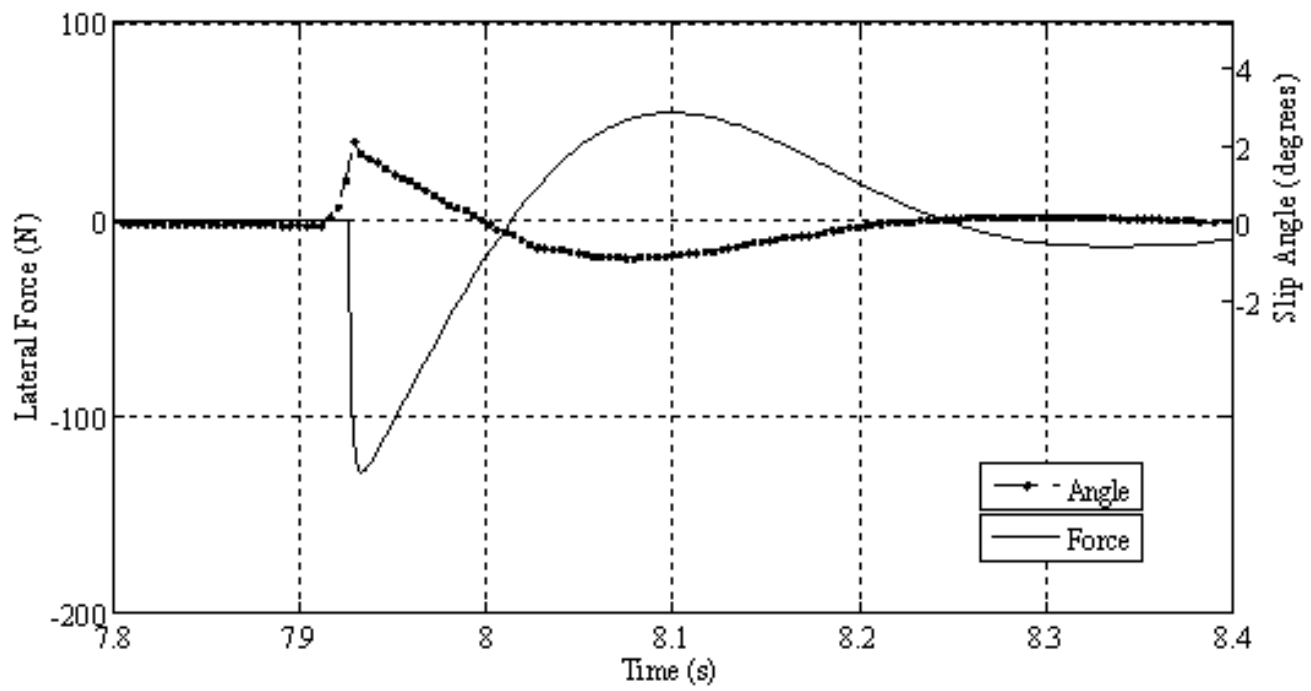

Fig. 3. Front tyre slip angle and resulting lateral force.

acceleration and braking force was assumed to be negligible in a time trial. A "thin-disk" wheel/tyre was modelled and the effects of tyre width were accounted for in the equations of motion rather than through physical tyre dimensions. Overturning moment due to side slip was also neglected (Blundell \& Harty, 2004). Tyres were assumed to be axially symmetric with no plysteer or conicity effects requiring bias correction at zero slip angle (Roland, 1973). The vertical tyre load was taken as the static bicycle/rider weight on the front/rear wheel and ignored variances due to motion.

\subsection{Simulation}

The full bicycle/rider model was simulated from rest and accelerated upright and straight-ahead to reach a steadystate speed of $11.1 \mathrm{~m} / \mathrm{s}$ after $\sim 7.5 \mathrm{~s}$. A transient steering input was applied at $\sim 7.9 \mathrm{~s}$ from the start comprising a step-input of $4^{\circ}$ to the right generating a bicycle yaw rate of $40^{\circ} / \mathrm{s}$. Model steer $/$ roll responses returned the bicycle to upright equilibrium on a new track by $9 \mathrm{~s}$ from the start when the simulation was terminated. Forces, moments and motions for front and rear tyres were recorded at the simulation time-step frequency $(\sim 0.01 \mathrm{~s})$ enabling results to be graphed and analysed. All results are presented as absolute values rather than proportional changes as these are more indicative of energy dissipation.

\subsection{Results}

Consider lateral force due to slip angle. The 4-degree initial steering input generated a front slip angle of $2.2^{\circ}$ and a peak lateral force of $130 \mathrm{~N}$ when tyre cornering stiffness was $3680 \mathrm{~N} / \mathrm{rad}$ and vertical load $338 \mathrm{~N}$ (Fig. 3).
When combined with a front wheel yaw velocity that peaked at $112^{\circ} / \mathrm{s}$, a peak power of $228 \mathrm{~W}$ was transferred from forward propulsion to lateral propulsion. Integrating the power profile over the simulation showed that the power transfer represented 8.4 J of work. An equivalent power transfer for the rear wheel was 7.7 J yielding a total forward-to-lateral work-done of $16.1 \mathrm{~J}$, all of which would have been applied to forward bicycle propulsion if straightrunning had been maintained.

Consider lateral force due to slip angle. A peak front wheel camber angle of $2.9^{\circ}$ resulted from the steering input which generated $17 \mathrm{~N}$ of lateral force (Fig. 4).

This can be treated as additive to the slip induced lateral force while the tyre model relationships remain linear. Rear wheel camber angle of $4^{\circ}$ was somewhat greater than front wheel camber as it was not reduced by steering geometry effects. As a proportion of total forwardto-lateral work-done, camber force contributed $16 \%$ compared to the slip force contribution of $84 \%$. This relationship was consistent with findings for motorcycle tyres at low camber angles, but larger than the typical $5 \%$ camber force contribution to car tyre forces (Sharp, 2007).

The tyre model also measured and applied forces associated with wheel angular velocity (for power calculations), combined slip/camber force and aligning/ overturning/rolling moments. Detailed results are available but have not been included here as being beyond the scope of this paper.

\subsection{Discussion}

The main aim of this section was to quantify the forces and moments generated by the bicycle tyre model in response to steering input and confirm that they were 


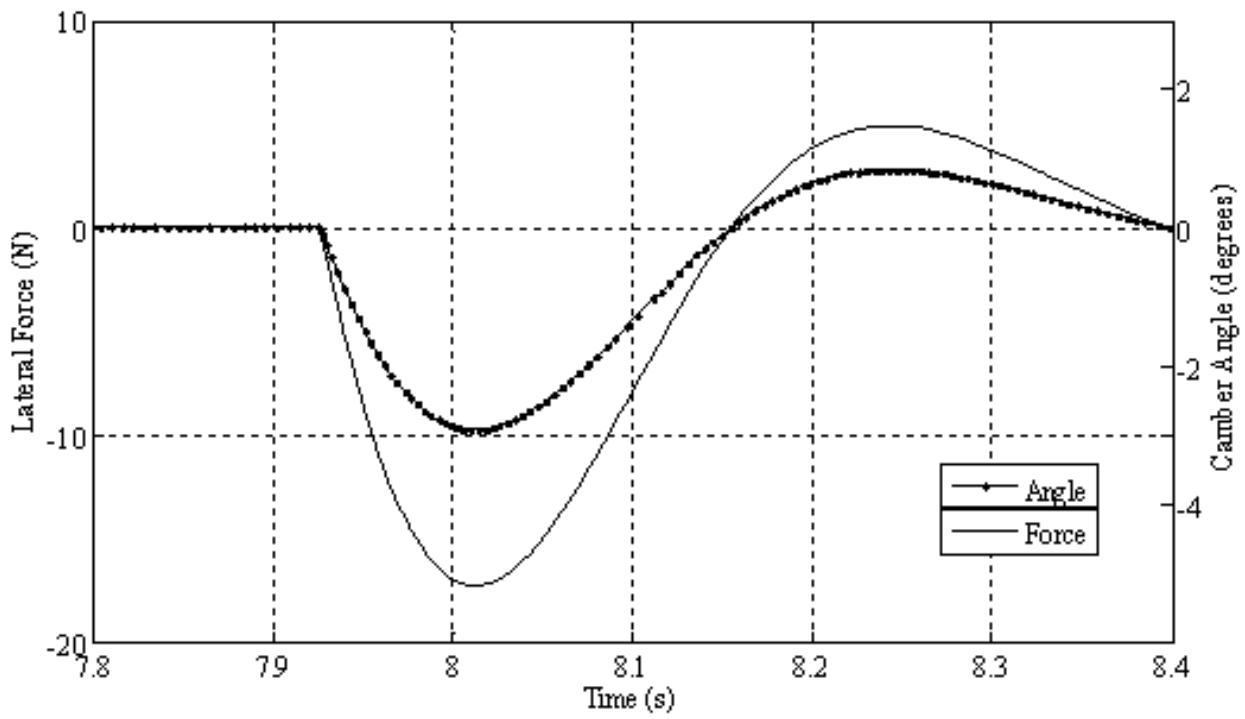

Fig. 4. Front tyre camber angle and resulting lateral force.

realistic. The few studies that have incorporated tyre models into bicycle handling simulations have reported eigenvalues relating to bicycle self-stability rather than directly calculating tyre forces (Limebeer \& Sharp, 2006; Sharp, 2007). Most bicycle field studies have been limited to measuring force and motion associated with the bicycle frame (e.g. steering angles and torques) as tyre forces can usually only be calculated indirectly from instrumentation.

However, Roland and Lynch (1972) conducted field testing with a simplified tyre testing machine towed behind a car and reported a mean cornering stiffness of $60 \mathrm{~N} /{ }^{\circ}$ at $3^{\circ}$ slip angle, $10^{\circ}$ camber angle and $330 \mathrm{~N}$ vertical load. Although not necessarily reproducing the response of a steered bicycle, the similarity of this result to the rear tyre force obtained in the current simulation $\left(62 \mathrm{~N} /{ }^{\circ}\right.$ at $3^{\circ}$ slip, $4^{\circ}$ camber and $338 \mathrm{~N}$ load) provides support for the validity of the tyre model, but with unresolved questions remaining on the contribution of camber to lateral force generation.

\section{Uncontrolled Stability Validation}

\subsection{Introduction}

The aim of this section was to validate a linearised version of the bicycle model by comparing stability mode eigenvalues with those reported by the "benchmark" bicycle model of Meijaard et al. (2007). Application of the "benchmark" model equations of motion to the present bicycle was possible due to "benchmark equivalent" equations of motion being available for download from $<$ http://ruina.tam.cornell.edu/research/topics/

bicycle mechanics/JBike6 web folder/index.htm $>$. The application software from that site which enabled calculation of eigenvalues was developed and validated by Dressel (2007).

\subsection{Methods}

A sub-model was extracted from the complete cycling model to compare the eigenvalues for the characteristic stability modes with those of the benchmark model. The full model was modified by reducing the rider to a rigid inert mass fixed to the rear frame. The investigation required upright straight-running at constant speed on a flat road so aerodynamic and gravitational resistive forces were removed. A constant velocity actuator was applied to the rear frame to launch the bicycle at the required speed. The front and rear tire models were removed leaving each wheel with two non-holonomic constraints enforcing pure rolling (no-slip) conditions. All other constraints and actuators were removed leaving the bicycle with only freedom to translate longitudinally/laterally and roll/ yaw/pitch/steer.

Ten separate simulations were run at velocities from 1 to $10 \mathrm{~m} / \mathrm{s}$ at $1 \mathrm{~m} / \mathrm{s}$ intervals with simulation duration of $10 \mathrm{~s}$ (or less if terminated by a bicycle capsize). The non-linear model was linearised for each velocity at an operating point $0.5 \mathrm{~s}$ into the simulation when start-up transients had decayed and the model approximated to steady state. A lateral perturbation of $10 \mathrm{~N}$ was applied to the chain stay directly above the rear contact point for $0.1 \mathrm{~s}$ after $1 \mathrm{~s}$ of straight-running. Eigenvalues were extracted from the mass matrix of the resulting state-space representation and graphed for the real weave, imaginary weave, castor and capsize modes. The JBike6 version of the benchmark model run was run with the same range of velocities and parameters that matched those of the present bicycle. 


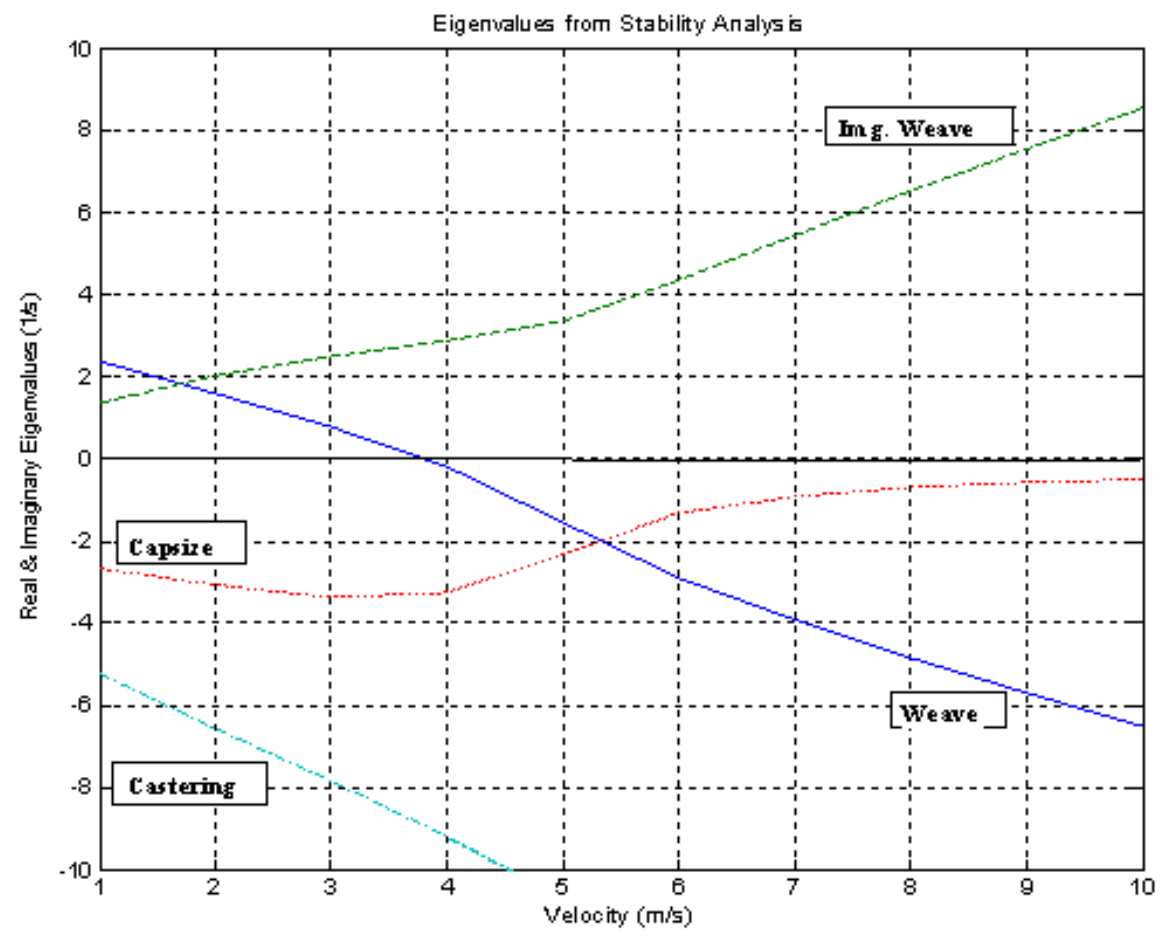

Fig. 5. Eigenvalues representing stability modes obtained from the current linearised model.

\subsection{Results}

The linearised model eigenvalues calculated over the speed range achieved low speed self-stability when the real weave mode eigenvalue changed from positive to negative at $3.8 \mathrm{~m} / \mathrm{s}$. No upper self-stability limit was found as the capsize mode eigenvalues remained negative over the tested speed range (Fig. 5).

Comparing these results to the benchmark model, the eigenvalue plots showed similar profiles for the real weave, imaginary weave and castering modes although the benchmark real weave zero crossing at $4.2 \mathrm{~m} / \mathrm{s}$ was slightly higher than the $3.8 \mathrm{~m} / \mathrm{s}$ for the present model. However, the benchmark model capsize at $6 \mathrm{~m} / \mathrm{s}$ was significantly different from the present model which remained selfstable up to the maximum tested velocity of $10 \mathrm{~m} / \mathrm{s}$.

\subsection{Discussion}

A linearised version of the present bicycle model generated eigenvalues which were consistent with the established benchmark values. In particular, the castering mode and real weave eigenvalues were similar between the two models. The weave zero crossing value was an important similarity as it indicated the transition from oscillatory instability to bicycle self-stability. The difference of $0.5 \mathrm{~m} / \mathrm{s}$ between the models was well within the variation that might be expected from the variances in design parameters (Dressel, 2007).
The capsize mode was the only eigenvalue that was clearly different between the benchmark and present model. The benchmark model showed the capsize eigenvalue becoming positive at $6 \mathrm{~m} / \mathrm{s}$ while the present model remained stable up to the $10 \mathrm{~m} / \mathrm{s}$ test limit. Additionally, given the trend of the graph plot, it seems unlikely that zero crossing would have occurred for the present model even if the test speed range had been increased. It was apparent, from examining eigenvalue graphs for similar bicycle configurations, that the capsize mode becomes positive over a particularly wide range of values. The experimental study of Kooijman, Schwab, \& Meijaard (2008) reported a zero crossing at $7.9 \mathrm{~m} / \mathrm{s}$ and exhibited a curvilinear capsize plot below $3 \mathrm{~m} / \mathrm{s}$ which was similar to the present model. Dressel (2007) used benchmark-equivalent equations of motion to report a zero crossing at $8 \mathrm{~m} / \mathrm{s}$ while a separate study produced by a benchmark co-author (Schwab, Meijaard, \& Kooijman, 2007) reported zero crossing at $\sim 7.896 \mathrm{~m} / \mathrm{s}$. This latter study also suggested that the positive capsize eigenvalue would again approach zero from above (i.e. become negative) as the speed increased further. In the same study, a hypothetical bicycle was modelled with zero trail and zero gyroscopic forces which showed the capsize mode remaining permanently negative. It therefore seems likely that the capsize mode zero crossing was dependent on specific bike geometry. 


\begin{tabular}{|c|c|c|c|c|c|c|c|c|c|c|c|c|c|}
\hline ID & $\begin{array}{l}\text { Hejght } \\
\text { (m) }\end{array}$ & $\begin{array}{c}\text { Cyclist } \\
\text { We ght } \\
\text { (kg) }\end{array}$ & $\begin{array}{l}\text { Total } \\
\text { Weight } \\
\text { (N) }\end{array}$ & $\begin{array}{l}\mathrm{BSA} \\
(\mathrm{sq} \mathrm{m})\end{array}$ & $\begin{array}{l}\text { Frortal } \\
\text { Area }^{a}\end{array}$ & $\begin{array}{c}\text { Drag } \\
\text { Coefficient }\end{array}$ & $\mathrm{CDA}$ & $\begin{array}{l}\text { Wind } \\
\text { Direction } \\
\text { (rad) }\end{array}$ & $\begin{array}{l}\text { Wind } \\
\text { Speed } \\
\text { (m/s) }\end{array}$ & $\begin{array}{l}\text { Actual } \\
\text { Time (s) }\end{array}$ & $\begin{array}{l}\text { Predicted } \\
\text { Time (s) }\end{array}$ & $\begin{array}{l}\text { Predicted } \\
\text { Varance } \\
\text { (s) }\end{array}$ & $\begin{array}{l}\text { Absohte } \\
\text { Varine }\end{array}$ \\
\hline 1 & 1.73 & 71 & 765 & 1.84 & 0.30 & 0.83 & 0.25 & -1.0 & 1.3 & 315 & 314 & -1 & $0.3 \%$ \\
\hline 2 & 1.80 & $6 ?$ & 736 & 1.85 & 0.29 & 0.89 & 0.26 & -0.8 & 2.2 & 335 & 349 & 14 & $4.2 \%$ \\
\hline 3 & 1.80 & 70 & 755 & 1.89 & 0.30 & 0.84 & 0.25 & -0.7 & 1.5 & 354 & 356 & 2 & $0.6 \%$ \\
\hline 4 & 1.83 & 79 & 844 & 2.01 & 0.32 & 0.78 & 0.25 & -1.2 & 3.9 & 346 & 348 & 2 & $0.6 \%$ \\
\hline 5 & 1.85 & 79 & 844 & 2.03 & 0.32 & 0.78 & 0.25 & -0.8 & 1.7 & 336 & 336 & 0 & $0.0 \%$ \\
\hline 6 & 1.78 & 81 & 863 & 1.99 & 0.33 & 0.80 & 0.26 & -0.4 & 2.9 & 350 & 354 & 4 & $1.1 \%$ \\
\hline 7 & 1.82 & 69 & 765 & 1.89 & 0.44 & 0.69 & 0.30 & -1.1 & 3.3 & 401 & 402 & 1 & $0.2 \%$ \\
\hline 8 & 1.78 & 73 & 795 & 1.90 & 0.45 & 0.66 & 0.30 & -0.7 & 2.0 & 372 & 377 & 5 & $1.3 \%$ \\
\hline 9 & 1.67 & 64 & 716 & 1.72 & 0.42 & 0.77 & 0.32 & -0.2 & 3.0 & 401 & 421 & 20 & $5.0 \%$ \\
\hline 10 & 1.83 & 93 & 990 & 2.15 & 0.52 & 0.65 & 0.34 & -0.6 & 2.0 & 378 & 381 & 3 & $0.8 \%$ \\
\hline 11 & 1.85 & 82 & 893 & 2.06 & 0.59 & 0.59 & 0.35 & -1.2 & 1.4 & 355 & 360 & 5 & $1.4 \%$ \\
\hline 12 & 1.81 & 78 & 800 & 1.98 & 0.58 & 0.64 & 0.37 & -0.7 & 2.1 & 375 & 384 & 9 & $2.4 \%$ \\
\hline 13 & 1.80 & 80 & 820 & 2.00 & 0.58 & 0.63 & 0.37 & -0.7 & 3.4 & 440 & 446 & 6 & $1.4 \%$ \\
\hline 14 & 1.80 & 83 & 810 & 2.03 & 0.60 & 0.62 & 0.37 & -0.7 & 1.3 & 370 & 369 & -1 & $0.3 \%$ \\
\hline
\end{tabular}

Fig. 6. Individual Data and Results. (Frontal Area ${ }^{\mathrm{a}}$. ID 1-5. Full T/T bike (Heil, 2005). ID 7-10. Road Bike Tribars (Heil, 2002). ID 11-14. Road Bike Hoods (Heil, 2002)).

\section{Field validation}

\subsection{Experimental design}

Fourteen experienced male time trial cyclists were recruited to be representative of good club/national level competitors (current time of 21-25 min for a 10 mile time trial). Participants were fully informed of the procedures and risks involved in the study before giving written informed consent. The study was approved by the university Ethics Committee.

Trials were conducted on the first 2.5 miles of the Cycling Time Trials course G10/42 near Dorking (UK) which was a straight, undulating dual-carriageway course. Participants rode their own bicycle after each was fitted with a PowerTap SL power meter (Saris Cycling Group, Madison, WI) or an SRM power meter (Schoberer Rad Messtechnik GmbH, Julich, DE). Both systems utilised a handlebar mounted screen that showed instantaneous propulsive power.

All systems were calibrated before each trial in accordance with the manufacturer's instructions. The PowerTap gives a $1.2 \%$ lower power reading compared to the "gold standard" SRM with power coefficients of variation (CV) of $1.8 \%$ and $1.5 \%$ respectively (Bertucci, Duc, Villerius, Pernin, \& Grappe, 2005; Paton \& Hopkins, 2006) reported similar power CV's of $1.5 \%$ for the PowerTap and $1.6 \%$ for the SRM but more importantly for this study, identified the mechanical component of the CV's as $0.9 \%$ and $1.1 \%$ respectively (equivalent to a $\sim 0.4 \%$ speed error). These later values were applicable to this study as power control largely eliminated biological variation.

A digital representation of the course section was obtained from a mapping CD (Memory Map Europe, Aldermaston, UK) and the course track (latitude/longitude) and height profile entered into the model. The mean gradient was $3 \%$ with a peak of $9 \%$, there were no appreciable flat parts and the start and finish were at the same height.

Each participant was tested separately on a single day starting with a warm-up/familiarisation. Testing was only conducted in good weather conditions (dry, wind $<5 \mathrm{~m} / \mathrm{s}$ ) and a rolling start was implemented for all runs. The wind strength and direction was measured with an anemometer (WindWorks, www.bythebeachsoftware.com) at a representative location on the course at the start and end of each day's trial.

The trial was completed at the participant's best selfselected 10 mile time trial pace with the objective of comparing the resulting time with the model prediction for that individual. To enable this comparison, the model was parameterised with the individual, bicycle and environmental data in respect of mass, aerodynamic coefficient of drag area (CDA) and wind strength/direction.

The CDA was computed from the product of cyclist/ bicycle frontal area and a drag factor (Fig. 6). Dependant on bicycle type, participants were divided into three categories comprising full $\mathrm{T} / \mathrm{T}$ bike, road bike with tribars and road bike with "hands on hoods". Frontal area for each bicycle/rider combination was obtained by applying rider weight to the regression equations for each bike category presented by Heil (2002) and Heil (2005). An individual CDA was calculated from the equations of Bassett, Kyle, Possfield, Broker, \& Burka (1999) who used wind tunnel testing to quantify aerodynamic resistance forces resulting from rider frontal area, riding position, bicycle structure, bicycle components, clothing and helmet. Wind strength and direction are shown in Figure 6 with a zero direction indicating wind from due south and negative values indicating wind veering clockwise. 


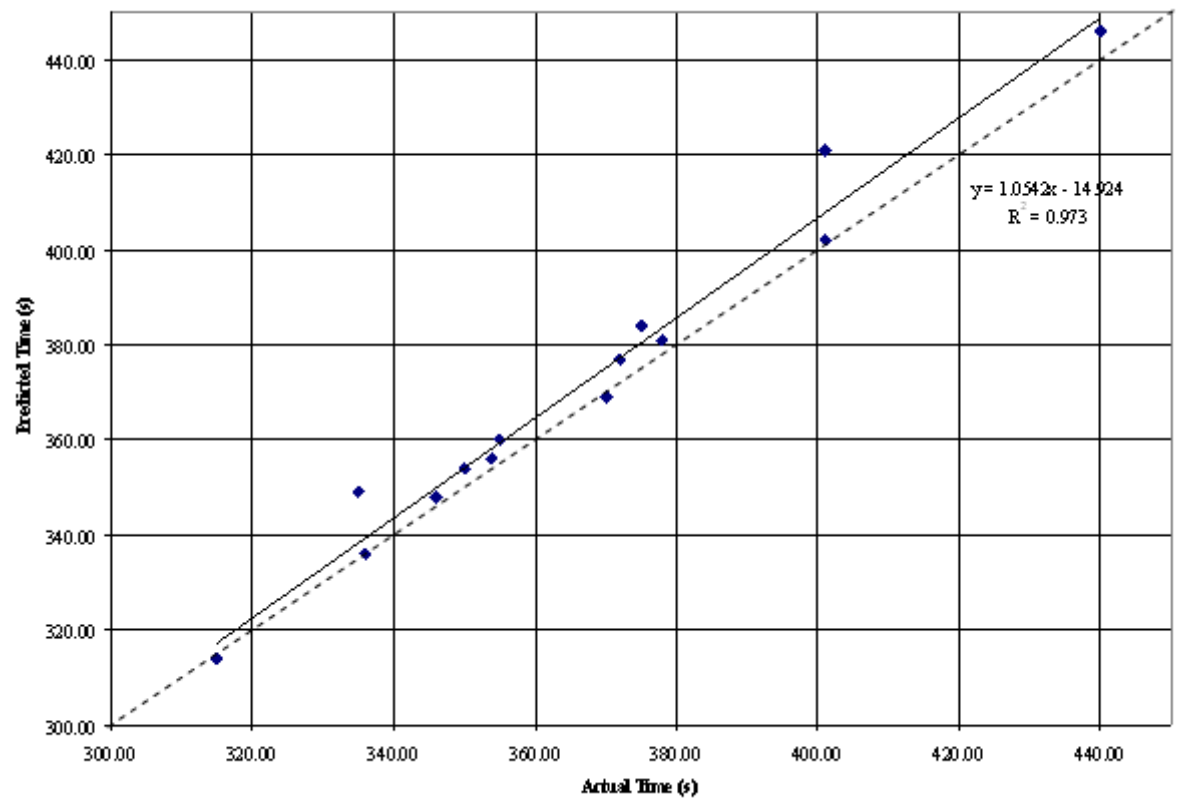

Fig. 7. Regression analysis of individual times.

\subsection{Data collection and analysis}

Time, power, speed and distance data for each trial were recorded on the power meter at $\approx 1 \mathrm{~s}$ intervals. In order to model predicted time for each individual, the recorded power profile for the trial was input to the model together with individual parameters for wind conditions, mass, and CDA.

\subsection{Statistical analysis}

Data sets were checked for normality with a ShapiroWilks test and for equal/unequal residual variance with an $F$-Test. Data were analysed with a paired $t$-test to identify any significant difference between predicted and actual completion time and with linear regression to identify any relationship between predicted and actual completion time. All data were analysed with SPSS (SPSS Inc, Chicago, IL) with significance set at $p \leq 0.05$.

\subsection{Results}

The required assumptions for the statistical analysis were confirmed with data sets normally distributed $(p>0.248)$ and an $F$-Test showing unequal variances between data sets $(F>1.194, p>0.288)$. The results are shown in Figure 6.

Mean predicted and actual times for the 14 participants were $371( \pm 35) \mathrm{s}$ and $366( \pm 32) \mathrm{s}$ respectively. The $5 \mathrm{~s}$ reduction in actual time was significantly different from the predicted time $(t=-3.104, p=0.008)$. The prediction error was $1.4 \%( \pm 1.5 \%)$. Actual and predicted times were closely related $\left(R^{2}=0.973\right)$ (Fig. 7$)$.

\subsection{Discussion}

The objective of experimental validation was to compare the time achieved by an individual in a field time trial with the time predicted for that individual by the model. The model-predicted individual time was $1.4 \%$ higher than the actual time. This compares well with the average error of $1.32 \%$ reported by the only two comparable models which combine first principles with road cycling (Martin et al., 1998; Olds et al., 1995).

Comparison with Martin et al. (1998) must be indirect as the measured dependant variable was power rather than completion time. However, it can be calculated from the presented data (for the $11 \mathrm{~m} / \mathrm{s}$ trials which were equivalent to this study) that the average model predicted time over the equivalent distance was $3.3 \mathrm{~s}$ faster than the actual time of 365 s giving a $0.9 \%$ error. This compares well with the $366 \mathrm{~s}$ actual time and $1.4 \%$ error in this study although the agreement was likely to be coincidental as the course of Martin et al. (1998) was flat (0.3\% gradient) and completely straight. Martin et al. (1998) also found that model predicted time was faster than actual time which was the reverse of this study. In part, this may reflect the absence of a traffic "towing" effect on their closed airfield course.

Olds et al. (1995) compared model predicted and actual times for 41 cyclists over a $26 \mathrm{~km}$ flat $(<0.5 \%$ gradient) course. The mean model predicted time was 0.74 min greater than the actual time of 42.8 min giving an error level of $1.73 \%$, similar to the $1.4 \%$ found in this study. However, Olds et al. (1995) reported a large error $\mathrm{SD}$ of $\pm 2.07 \mathrm{~min}$ and range of +5.56 to -3.15 min which they attributed to less accurate modelling of the sixteen 
non-competitive cyclists included in the study.

In conclusion, the experimental validation suggests that the model was an accurate representation of road time trial cycling. Specific kinematic and kinetic variables were not measured during the time trial for comparison with modelled values, but it seems unlikely that accumulated errors would sum to a valid result. However, it must be accepted that the validation was specific to a particular time trial course and conditions which may not hold true for all road cycling. Further studies with measuring devices fitted to the bicycle will be needed if the model validity is to be extrapolated to a wider range of conditions.

\section{Limitations and future development}

The present model has a number of limitations, many of which are currently being addressed. Beta versions of the model are available that incorporate developments not yet loaded into the live model. Identified model limitations are:

- Cadence is currently uncontrolled due to the absence of a gear system. A system is being developed based on a car automatic gearbox.

- Pedalling should be driven by joint torques at the ankle, knee and hip rather than pedal forces.

- The present model applies no rider forces to the handlebars in opposition to the pedalling down-stroke. These forces are significant at high power levels and should be applied in both vertical and longitudinal axes by each arm (Stone \& Hull, 1995).

- Steering torque is currently applied directly to the steering joint rather than being applied as a couple to the handlebars.

\section{Summary}

This study has described a comprehensive model of road cycling that combines bicycle dynamics, pedalling rider and an external environment in a single unified system. The model can be parameterised with bicycle, rider and course characteristics and actuated with force or motion profiles to simulate competitive field cycling. A variable step ODE solver integrates output that can be used to evaluate the effect of tuning mechanical variables on cycling performance. The model has been validated with reference to existing models in the literature and by comparing predicted completion time over a time trial course with field experiment data.

Further studies with the validated model will investigate the mechanical performance effects of bike/ rider weight distribution, saddle position, crank length, effect of pedalling style on tyre forces and the contribution of muscular/non-muscular forces to pedalling.

\section{References}

Bailey, M., Nesi, X., Passfield, L., \& Carter, H. (2006). Comparison of cycle crank torque computed from forces applied to the pedals and measured with an SRM ergometer. Proceedings of the European College of Sport Science Congress, July 5th-8th, Lausanne, Switzerland.

Bassett, D.R., Jr., Kyle, C.R., Passfield, L., Broker, J.P., \& Burke, E.R. (1999). Comparing cycling world hour records, 1967-1996: modeling with empirical data. Medicine and Science in Sports and Exercise, 31(11), 1665-1676.

Bertucci, W., Duc, S., Villerius, V., Pernin, J.N., \& Grappe, F. (2005). Validity and reliability of the powertap mobile cycling powermeter when compared with the SRM Device. International Journal of Sports Medicine, 26(10), 868-873.

Blundell, M., \& Harty, D. (2004). The Multibody systems approach to vehicle dynamics. Oxford, UK: ButterworthHeinemann.

Caldwell, G.E., Li, L., McCole, S.D., \& Hagberg, J.M. (1998). Pedal and crank kinetics in uphill cycling. Journal of Applied Biomechanics, 14(3), 245-259.

Carvallo, M.E. (1900). Théorie du mouvement du monocycle et de la bicyclette. Journal de L'École Polytechnique, 5(2), $119-188$.

Dressel, A. (2007). The Benchmarked linearized equations of motion for an idealized bicycle. Ph.D. Thesis.

http://ecommons.library.cornell.edu/handle/1813/ 3615 ? mode $=$ full.

Gillespie, T.D. (1992). Fundamentals of vehicle dynamics. Warrendale, PA: SAE.

Heil, D.P. (2002). Body mass scaling of frontal area in competitive cyclists not using aero-handlebars. European Journal of Applied Physiology, 87(6), 520-528.

Heil, D.P. (2005). Body size as a determinant of the 1-h cycling record at sea level and altitude. European Journal of Applied Physiology, 93(5-6), 547-554.

Hull, M.L., \& Jorge, M. (1985). A method for biomechanical analysis of bicycle pedalling. Journal of Biomechanics, 18(9), 631-644.

Kooijman, J.D.G., Schwab, A.L., \& Meijaard, J.P. (2008). Experimental validation of a model of an uncontrolled bicycle. Multibody System Dynamics, 19(1-2), 115-132.

Kyle, C.R. (1994). Energy and aerodynamics in bicycling. Clinics in Sports Medicine, 13(1), 39-73.

Kyle, C.R. (2003). Selecting Cycling Equipment. 2nd Ed. Champaign, IL: Human Kinetics.

Limebeer, D.J.N., \& Sharp, R.S. (2006). Bicycles, motorcycles and models. IEEE Control Systems Magazine, 36, 34-61.

Martin, J.C., Milliken, D.L., Cobb, J.E., McFadden, K.L., \& Coggan, A.R. (1998). Validation of a mathematical model for road cycling power. Journal of Applied Biomechanics, 14(3), 276-291.

Meijaard, J.P., Papadopoulos, J.M., Ruina, A., \& Schwab, A.L. (2007). Linearized dynamics equations for the balance and steer of a bicycle: a benchmark and review. Proceedings of the Royal Society of London, A463, 1955-1982. 
Neptune, R.R., \& Hull, M.L. (1998). Evaluation of performance criteria for simulation of submaximal steady-state cycling using a forward dynamic model. Journal of Biomechanical Engineering, 120(3), 334-341.

Olds, T.S., Norton, K.I., Lowe, E.L., Olive, S., Reay, F., \& Ly, S. (1995). Modeling road-cycling performance. Journal of Applied Physiology, 78(4), 1596-1611.

Paton, C.D., \& Hopkins, W.G. (2006). Ergometer error and biological variation in power output in a performance test with three cycle ergometers. International Journal of Sports Medicine, 27(6), 444-447.

Redfield, R., \& Hull, M.L. (1986). On the relation between joint moments and pedalling rates at constant power in bicycling. Journal of Biomechanics, 19(4), 317-329.

Roland, R.D. (1973). Computer simulation of bicycle dynamics. Proceedings of the ASME Symposium Mechanics and Sport, 35-83.

Roland, R.D., \& Lynch, J.P. (1972). Bicycle dynamics tire characteristics and rider modeling. Cornell Aeronautical Laboratory, Report no. YA-3063-K-2.
Schwab, A.L., Meijaard, J.P., \& Kooijman, J.D.G. (2007). Some recent developments in bicycle dynamics. Proceedings of the 12th World Congress in Mechanism and Machine Science.

Sharp, R.S. (2007). Optimal stabilization and path-following controls for a bicycle. Journal Proceedings of the Institution of Mechanical Engineers, Part C, 221(4), 415427.

Soden, P.D., \& Adeyefa, B.A. (1979). Forces applied to a bicycle during normal cycling. Journal of Biomechanics, 12(7), 527-541.

Stone, C., \& Hull, M.L. (1995). The effect of rider weight on rider-induced loads during common cycling situations. Journal of Biomechanics, 28(4), 365-375.

Swain, D.P. (1997). A model for optimizing cycling performance by varying power on hills and in wind. Medicine and Science in Sports and Exercise, 29(8), 1104-1108.

Whipple, F.J.W. (1899). The Stability of the motion of a bicycle. Quarterly Journal of Pure and Applied Mathematics, 30, 312-348. 